Ergo

\title{
An Argument for Objective Possibilism
}

\author{
PETER A. GRAHAM \\ University of Massachusetts Amherst
}

\begin{abstract}
Two debates in normative ethics are the Subjectivism/Objectivism debate and the Actualism/Possibilism debate. Both have settled into rather intractable stalemates. My goal is to break through these stalemates and establish that the correct moral theory must be an Objective Possibilist one. I first argue that no Subjective Possibilism is plausible. I then argue that Actualism cannot adequately accommodate the intuitive moral data in cases of permissible beneficial sacrifice-cases in which it is permissible to harm some in order to prevent harm from befalling others. Insofar as Actualism and Subjective Possibilism are both false, some version of Objective Possibilism must be true.
\end{abstract}

$\mathrm{P}$ RESENTLY there are two very contentious debates ongoing in normative ethics: the Actualism/Possibilism debate and the Subjectivism/Objectivism debate. I argue that the correct moral theory must be an Objective Possibilist one. In Sections 1 and 2, I explain what is at issue in each of these debates. Then, in Section 3, I argue that Subjectivism implies Actualism; in particular, I argue that the only plausible way of constructing a Subjective Possibilism yields results no Subjectivist could find plausible. And then, finally, in Sections 4 and 5, I argue that Actualism is false; in particular, I argue that Actualism yields implausible verdicts in certain cases involving permissible beneficial sacrifice-cases in which it is permissible to cause harm to some in order to prevent harm from befalling others.

Contact: Peter Graham <pgraham@philos.umass.edu> 


\section{Subjectivism and Objectivism}

The debate between Subjectivists and Objectivists about morality is a debate about what facts the moral status of an agent's actions supervenes upon. ${ }^{1}$ Subjectivists maintain that an act's moral status supervenes only on the agent's subjective circumstances. ${ }^{2,3}$ Objectivists deny this. ${ }^{4}$ The easiest way to see what is in dispute is to look at a case about which they disagree.

Switch: Chen's subjective circumstances indicate that flipping the light switch will help Sanchez find her wallet and do nothing else. In fact, unbeknownst to Chen, her objective circumstances are such that if she flips the switch a bomb will go off in Cairo, killing many innocent civilians.

Chen has two options:

FLIP: flip the switch

$\sim$ FLIP: not flip the switch

1. Subjectivists (of different varieties) about morality include Sidgwick (1907), Prichard (1949), and William Ross (1939). Objectivists about morality include Moore (1903), William Ross (2002), Feldman (1986), Thomson (1990), and Smith (2014). Jackson (1991; 2014), Zimmerman (2008; 2014), and Kiesewetter (2011) all hold that an action's moral status only partly, though predominantly, supervenes on the agent's subjective circumstances. This makes them, technically, Objectivists on my definitions. Nevertheless, the arguments I go on to offer below work equally well against their views as they do against Subjectivist theories.

2. Different Subjectivists differ with respect to what they take an agent's subjective circumstances to comprise. Belief Subjectivists take the relevant circumstances to comprise the agent's beliefs. Evidence Subjectivists take the relevant circumstances to comprise the agent's evidence.

3. There is a potentially serious complication for Subjectivism. Plausibly, the moral status of an action supervenes on what the agent in question can do. For one thing, if 'Ought' Implies 'Can' is true, this is most certainly the case. For another, whether an action is permissible will often depend on what one's alternatives are-saving only A is permissible if one's only alternative is doing nothing; it is not if one can also save both A and B. However, what an agent can do surely is, at least in part, an objective matter, and thus one about which one's beliefs and evidence might well be mistaken. How a Subjectivist can accommodate this point given the standard motivation for Subjectivism - that morality must be action-guiding and that what one morally ought to do should be, at least in principle, accessible to one-isn't immediately clear. Insofar as this is a knot the Subjectivist can't untangle, all the better for my ambitions in this paper: if Subjectivism is untenable on its own, then that in conjunction with my argument against Actualism in Section 5 is sufficient to establish my conclusion, viz., that some form of Objective Possibilism is true. (It should be noted, however, that some Subjectivists, Zimmerman, 2008, for instance, do not motivate their Subjectivism by appeal to the action-guidingness and in-principle-accessibility of what one morally ought to do.)

4. On a more restricted definition of Objectivism, the moral status of an agent's action is a function solely of her objective circumstances. For the purposes of my argument, I have chosen a more inclusive definition of Objectivism, viz., one according to which it is merely the denial of Subjectivism. This definition allows that the moral status of an agent's action might partly supervene on her subjective circumstances. Establishing the truth of the more restricted notion of Objectivism would take an argument more ambitious than the one I offer.

Ergo •vol. 6, no. 8・2019 
According to Subjectivists, it is morally permissible for Chen to FLIP; everything she believes and all of her evidence indicates that flipping the switch will cause no one harm and will help Sanchez find her wallet. According to Objectivists, it would be morally impermissible for Chen to FLIP and, furthermore, she is morally obliged to FLIP; flipping the switch will cause a bomb to go off killing many innocent civilians and it is wrong to kill many innocent civilians.

Some try to defuse the debate between Subjectivists and Objectivists by distinguishing two different senses of 'permissible'. According to this reply, there is both a subjective sense of 'permissible' and an objective sense of 'permissible'. According to the subjective sense of 'permissible' it is permissible for Chen to FLIP in Switch. And according to the objective sense of 'permissible' it is not morally permissible for Chen to FLIP in Switch. Subjectivists and Objectivists are just talking past each other, so goes this reply, because they're talking about different senses of 'permissible'.

This attempt to defuse the debate between Subjectivists and Objectivists fails. What is at issue between them is what it is for an action to be permissible in the sense of 'permissible' that we are trying to give an account of when doing moral theory. That is, it is the sense of 'permissible' over which Utilitarians and Kantians disagree when they offer their respective moral theories. When doing moral theory what we're after is an account of the notion of permissibility that is of concern to the morally conscientious person when she deliberates about what to do. In her deliberations about what to do, the morally conscientious person is concerned to act permissibly and avoid acting impermissibly. But in her deliberations the morally conscientious person isn't employing two different senses of 'permissible'. There is just one sense of 'permissible' that the morally conscientious person is interested in when in her deliberations she is concerned to act permissibly and avoid acting impermissibly. ${ }^{5}$ And so, there is no dissolving of the dispute between Subjectivists and Objectivists by distinguishing senses of 'permissible', for it is precisely that particular sense of 'permissible' about which they disagree. In other words, the question is: is Subjectivism or Objectivism true of the notion of moral permissibility which is of ultimate concern to the morally conscientious person in her

5. Though there is only one sense of 'permissible' the morally conscientious person is interested in in her deliberations about what to do, that sense of 'permissible' needn't be equivalent to what in fact a morally conscientious person might end up doing. The morally conscientious person might opt to do what she knows is morally impermissible in situations in which acting moderately wrongly is the only way she can avoid risking acting very seriously wrongly, or in situations in which acting moderately morally wrongly is the only way to avoid acting much more seriously wrongly overall. Zimmerman $(2008 ; 2014)$ seems to identify the sense of moral permissibility of concern to the morally conscientious person with what such a person would non-akratically do. Bykvist (2009) and Graham (2010) explicitly reject that identification. 
deliberations about what to do? This question cannot be dodged by splitting senses of 'permissible'. ${ }^{6}$

So much for the Subjectivism/Objectivism debate. 7 Another live debate in contemporary normative ethics is that between Actualists and Possibilists.

\section{Actualism and Possibilism}

Actualists maintain, and Possibilists deny, that a person's potential future voluntary behavior-what she will later do were she to do some particular thing now - is relevant to her present moral obligations. ${ }^{8,9}$ As before, an example will help illustrate what's in dispute:

Headache: On Monday, Patient has an excruciating headache. Though it will go away on its own in five hours, drug D will cure it immediately. However, as D is a very potent drug, if it is administered on Monday, drug E must be administered on Tuesday in order to counter its side effects, otherwise Patient will die. Doctor can administer D on Monday, but she knows that if she does so, even though she will be able to administer E on Tuesday, because of her own laziness then, she won't.

Doctor has two options on Monday:

GIVE D: administer D to Patient

$\sim$ GIVE D: not administer D to Patient

6. This rebuttal of the attempt to defuse the debate between Subjectivists and Objectivists by positing different senses of 'permissible' is employed in Zimmerman (1996; 2008).

7. I should note that even if it is true that moral permissibility is fully objective, it doesn't follow from this that a derivative notion of subjective permissibility (one derived from the objective notion of permissibility) couldn't be philosophically useful-perhaps in connection with facts about blameworthiness/praiseworthiness and virtue/vice. Thanks to an anonymous referee for encouraging me to highlight this point.

8. Actualists include Goldman (1976), Sobel (1976), Jackson and Pargetter (1986), Goble (1993), and Jackson (2014). And, though they cast their various principles in terms of intentions, as opposed to actions, Portmore (2011) and Jacob Ross (2012) are also Actualists in my sense of the term. Possibilists include Goldman (1978), Greenspan (1978), Thomason (1981), Humberstone (1983), Feldman (1986), Zimmerman (1996, 2008), Vessel (2009, 2015), and Vorobej (2000). Like Portmore and Ross, Cohen and Timmerman (2016) cast their principle in terms of intentions, and they call themselves 'Hybridists', but they are Possibilists in my sense of the term.

9. Some Actualists (Jackson and Pargetter 1986, for instance), but not all (Portmore 2011, for instance), take the debate to be over the relevance both of one's potential future and of one's potential present voluntary behavior to one's present moral obligations. I focus only on Actualism's commitment to the relevance of one's potential future voluntary behavior to one's present moral obligations because that is something to which all versions of Actualism are committed. 
Possibilists contend that Doctor is morally obliged to GIVE D on Monday. Actualists maintain not only that Doctor is not morally obliged to GIVE D on Monday, but also that she's in fact morally obliged to $\sim$ GIVE D. The Actualist points out that Doctor's administering D to Patient on Monday would have disastrous consequences - Patient will die on Tuesday if Doctor administers D on Monday. The Possibilist counters that Doctor is morally obliged to do the best she can for Patient and there is a course of action open to her-administer D on Monday and then administer E on Tuesday - in which she cures Patient without killing her.

I'll say more about what's at issue in the Actualism/Possibilism debate in Section 4. But for now just note that the Actualist sees an agent's own potential future voluntary actions as being relevant to what she morally ought to do exactly as she sees those of any other agent. ${ }^{10}$ The Possibilist, on the other hand, thinks that the way an agent's own potential future voluntary behavior is relevant to her present moral obligations is very different from the way that of others is. If you will go on to do something horrible to an innocent person, A, if I assist someone else, B, then that provides me with a reason not to assist B; however, if I myself will go on to do something horrible to A, something I would easily be able to avoid doing, if I assist B, that fact gives me no reason not to assist $B$. The dispute between Actualists and Possibilists, then, is a dispute about how tightly, if at all, morality binds one to one's own agency across time.

I side with the Possibilist here and will offer arguments against Actualism later. First, however, I aim to show that Subjectivism and Possibilism make uncomfortable bedfellows.

\section{The Untenability of Subjective Possibilism}

Actualism and Possibilism are theses about the relevance of certain objective facts to a person's moral obligations - what she will do, in the case of Actualism, and what she will be able to do, in the case of Possibilism. Subjectivism is a thesis according to which all that is relevant to what a person morally ought to do is what she believes about, or what her evidence indicates about, the world, ${ }^{11}$ and not any objective facts. Actualism and Possibilism are thus both, strictly speaking, incompatible with Subjectivism. You might think, however, that there are Subjective analogues of Actualism and Possibilism and that there is as live a debate between them as there is between Objective Actualists and Objective Pos-

10. Woodard (2009) also points this out.

11. Among Subjectivists there is also a debate about whether all that is relevant to a person's moral obligations are her beliefs about, or her evidence concerning, factual matters, or whether also relevant are her beliefs about, or her evidence concerning, moral matters. 
sibilists. This is not the case. The only way I can see of translating Possibilism into a Subjective moral framework results in a theory that is untenable by any Subjectivist's lights. Thus, if Subjectivism about moral obligation is true, then Subjective Actualism is the only game in town.

How exactly should Actualism and Possibilism be understood from a Subjectivist perspective? Start with Actualism. For Objective Actualism, one's own potential future voluntary actions are relevant to one's moral obligations in the very same way as are any other possible future events. So too, then, should this be the case for Subjective Actualism. According to the most plausible version of Subjective Actualism, however, possible future events are relevant to one's own moral obligations by entering into one's expected deontic value calculations in the standard way: what an agent morally ought to do is choose the alternative available to her at a time, $t$, such that taking it has the highest expected deontic value of all the alternatives available to her at that time. ${ }^{12}$ And the expected deontic value of each of her alternatives at $t$ is the sum of the products for each of the possible total outcomes of that alternative of the probability of the outcome's occurrence given that the alternative is chosen and the deontic value of the outcome's occurrence. ${ }^{13}$ For a Subjective Actualist, then, the future voluntary actions of an agent will enter into this calculation in just the way the occurrence of any other event will.

As an example, consider Figure 1, which illustrates the tree of possible fu-

12. I consider the expected deontic value approach to be the most plausible version of Subjective Actualism for a couple reasons. First, it seems to be the only plausible way of translating a consequentialist moral theory into a Subjective Actualist framework. And whether the correct moral theory happens to be consequentialist or not, it must, at least, have a consequentialist component. That is, whatever the correct moral theory happens to be, it must take the consequences of an action to at least be morally relevant (the Kantian would, of course, demur) and the most plausible way of taking consequences to be morally relevant is the expected deontic value approach. Second, given that a moral theory can take account of non-consequentialist constraints and permissions by factoring such things into the deontic values of the possible worlds corresponding to an agent's alternatives, many, if not all, non-consequentialist moral theories should be translatable into an expected deontic value model. What is necessary for the expected deontic value approach to go through, however, is that the correct moral theory, whatever it happens to be, yield cardinal rankings of possible worlds corresponding to agents' alternatives, thereby delivering numerical values for the various deontic values used in the expected deontic value calculation. I assume that the correct moral theory will deliver such rankings. (More on this assumption below; see Footnote 25.) One final point. Even if I'm wrong that all plausible subjective moral theories can be captured on the expected deontic value approach, it is at least one approach, and a plausible one at that, to formulating a subjective moral theory, and so my arguments, should they succeed, will still be of value, for my conclusions should still hold for all expected deontic value-based subjective moral theories.

13. By 'deontic value' I'm simply referring to the measure by which a substantive moral theory deontically ranks the outcomes of a particular choice situation. I am not here presupposing that something like utilitarianism, or even consequentialism, is the correct substantive moral theory. See Zimmerman (1996) and (2008) on the appeal to deontic value in formulating moral theories. 


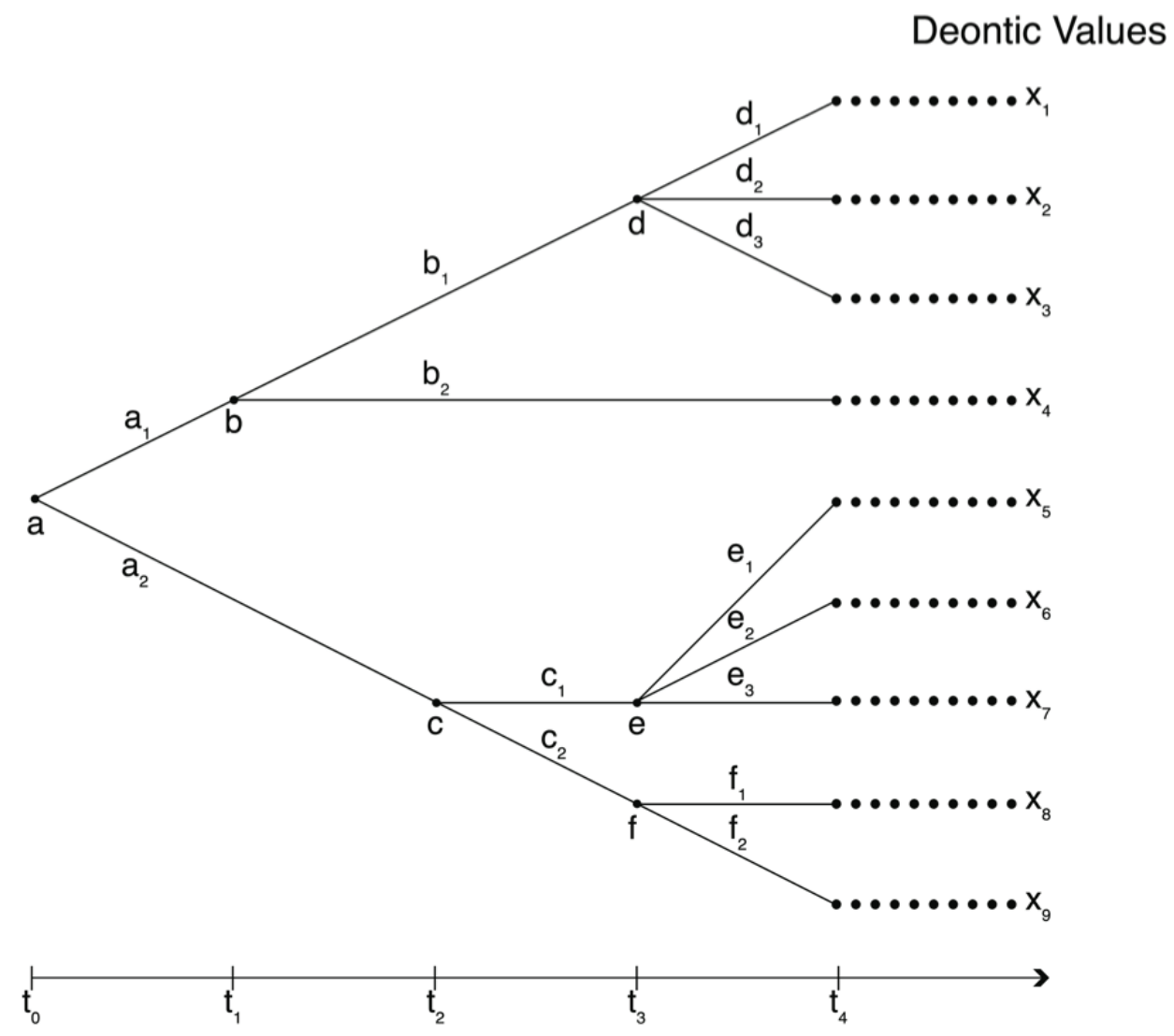

Figure 1.

tures for some choice of an agent, $S$, at time, $t_{0}$. The node, $a$, represents $S^{\prime}$ s choice between two options, $a_{1}$ and $a_{2}$ at $t_{0}$. There are five other nodes on the tree, two of which $-c$ and $d$-correspond to potential future choices of $S$; the other three remaining nodes $-b, e$, and $f$-correspond to potential non-choice branching events. The deontic values of the various possible outcomes, $x_{1}-x_{9}$, represent the cardinal rankings of the various outcomes according to the moral theory, whichever it so happens to be, that $S^{\prime}$ s evidence supports. ${ }^{14}$ Associated with each event is the probability of its occurrence conditional on the occurrence of all the events preceding it along the tree. So, for example, the probability associated with the segment, $b_{1}$, connecting nodes $b$ and $d, \mathrm{P}\left(b_{1} \mid a_{1}\right)$, is the probability of the occurrence of $b_{1}$ at $t_{1}$ conditional on the occurrence of $a_{1}$ at $t_{0}$. And the probability

14. A moral theory like that of Jackson (1991), which combines subjective and objective elements would use for the deontic values here whatever the deontic values are according to the true objective moral theory, whichever it happens to be. The arguments I go on to offer against Subjective Possibilism would work equally well against a Possibilist version of Jackson's theory as well. 
associated with the segment, $f_{2}$, extending out of node $f$ toward the end of the tree, $\mathrm{P}\left(f_{2} \mid a_{2} \& c_{2}\right)$, is the probability of the occurrence of $f_{2}$ at $t_{3}$ conditional on the occurrence of both $a_{2}$ at $t_{0}$ and $c_{2}$ at $t_{2}$. The expected deontic value for each of $S^{\prime} \mathrm{s}$ two choices, $a_{1}$ and $a_{2}$, can thus be straightforwardly calculated:

$$
\begin{aligned}
\operatorname{EDV}\left(a_{1}\right)= & \mathrm{P}\left(b_{1} \mid a_{1}\right) \mathrm{P}\left(d_{1} \mid a_{1} \& b_{1}\right)\left(x_{1}\right)+\mathrm{P}\left(b_{1} \mid a_{1}\right) \mathrm{P}\left(d_{2} \mid a_{1} \& b_{1}\right)\left(x_{2}\right)+\mathrm{P}\left(b_{1} \mid a_{1}\right) \\
& \mathrm{P}\left(d_{3} \mid a_{1} \& b_{1}\right)\left(x_{3}\right)+\mathrm{P}\left(b_{2} \mid a_{1}\right)\left(x_{4}\right) \\
\operatorname{EDV}\left(a_{2}\right)= & \mathrm{P}\left(c_{1} \mid a_{2}\right) \mathrm{P}\left(e_{1} \mid a_{2} \& c_{1}\right)\left(x_{5}\right)+\mathrm{P}\left(c_{1} \mid a_{2}\right) \mathrm{P}\left(e_{2} \mid a_{2} \& c_{1}\right)\left(x_{6}\right)+\mathrm{P}\left(c_{1} \mid a_{2}\right) \\
& \mathrm{P}\left(e_{3} \mid a_{2} \& c_{1}\right)\left(x_{7}\right)+\mathrm{P}\left(c_{2} \mid a_{2}\right) \mathrm{P}\left(f_{1} \mid a_{2} \& c_{2}\right)\left(x_{8}\right)+\mathrm{P}\left(c_{2} \mid a_{2}\right) \mathrm{P}\left(f_{2} \mid a_{2} \& c_{2}\right)\left(x_{9}\right)
\end{aligned}
$$

And according to the Subjective Actualist, whichever of $a_{1}$ and $a_{2} S$ ought to take will be determined by which of $\operatorname{EDV}\left(a_{1}\right)$ and $\operatorname{EDV}\left(a_{2}\right)$ is higher. (If $\operatorname{EDV}\left(a_{1}\right)=$ $\operatorname{EDV}\left(a_{2}\right)$ then both $a_{1}$ and $a_{2}$ are permissible.)

How about Subjective Possibilism? Objective Possibilism treats the moral relevance of all future events, except the future actions of the agent herself, in exactly the same way as Objective Actualism does. Likewise, Subjective Possibilism should adopt the same moral framework as Subjective Actualism with respect to all possible future events except the possible future voluntary actions of the agent herself. Whereas the Subjective Actualist thinks that the likelihood that the agent herself will perform some future voluntary action, at $t_{2}$, given that she makes a particular choice, $a_{1}$, among her alternatives at $t_{1}$ is relevant to whether she morally ought to choose $a_{1}$, the Subjective Possibilist thinks it isn't. All that matters for the Subjective Possibilist is what she could do at $t_{2}$ given that she chooses $a_{1}$ at $t_{1}$. (Or, more precisely, all that matters for the Subjective Possibilist is what she believes at $t_{1}$, or what her evidence at $t_{1}$ indicates, that she could do at $t_{2}$ given that she chooses $a_{1}$.) In particular, all that matters for the Subjective Possibilist is which of the alternatives that might be available to her at $t_{2}$ were she to choose $a_{1}$ at $t_{1}$ is such that it would have the highest expected deontic value were she thereafter at all times to always do what has the highest expected deontic value at those times.

Here, then, is how to think of how the Subjective Possibilist's moral theory differs from that of the Subjective Actualist's. For an agent, $S$, at a time, $t$, there is the corresponding tree of possible futures from which the Subjective Actualist determines the expected deontic value of each of $S^{\prime}$ 's alternatives at $t$. The Subjective Possibilist takes that tree and "prunes" it back in the following way: at every node in the tree corresponding to a possible future choice of $S^{\prime}$ s, the Subjective Possibilist chops off every branch except the one corresponding to the choice with the highest expected deontic value at that time assuming she always chooses the option with the highest deontic value thereafter. (In effect, this chopping off procedure is equivalent to setting the probability of the se- 


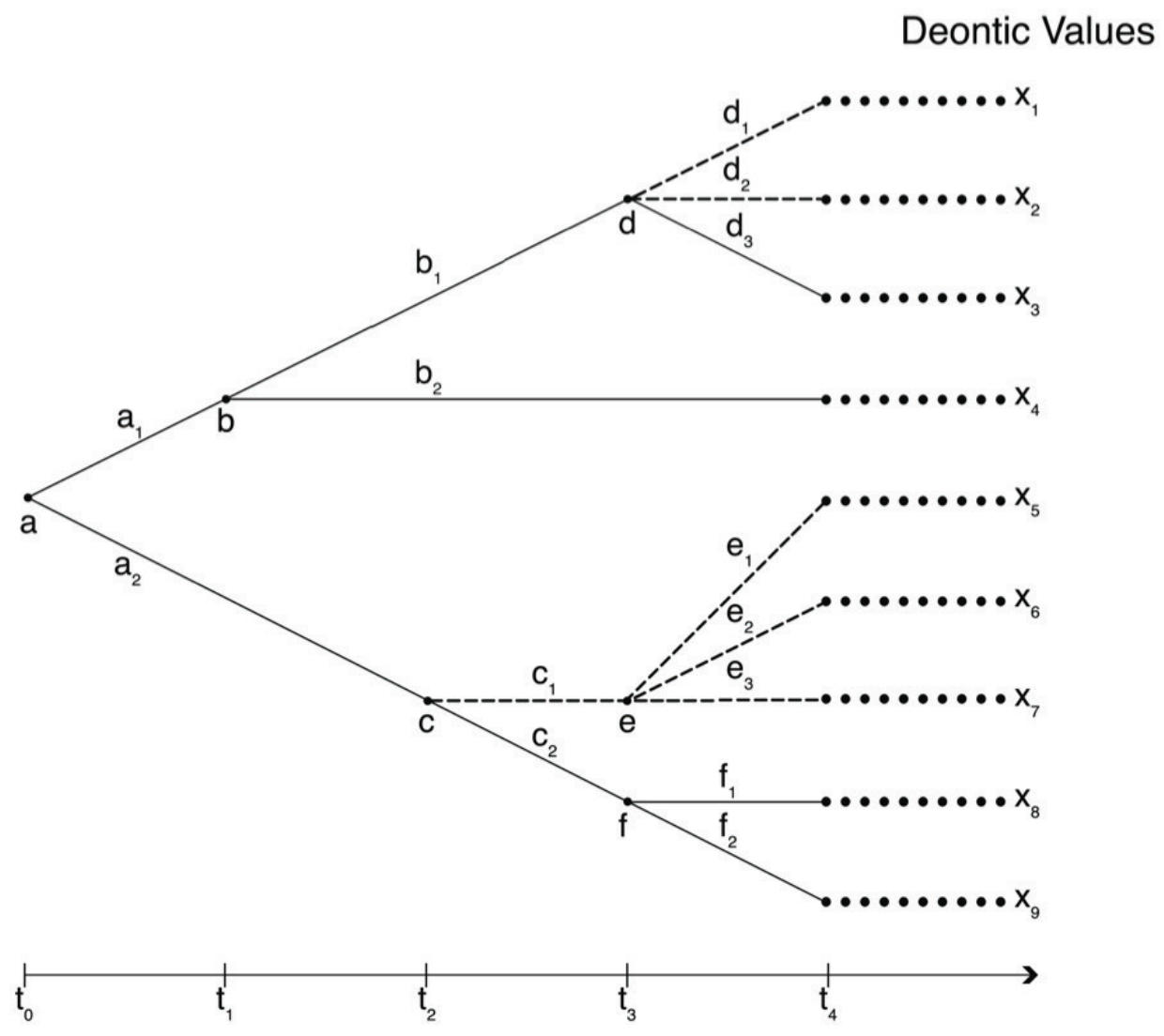

Figure 2

lected branch - the one not "chopped off" - to 1 and setting the probabilities of all the other branches - those "chopped off" - to o.) And whereas the Subjective Actualist holds that the alternative which the agent ought to take is the one with the highest expected deontic value, the Subjective Possibilist, on the other hand, holds that the alternative which she ought to take is the one with the highest expected deontic value*, where the expected deontic value* of an alternative is calculated in exactly the same way its expected deontic value is except that the probabilities used are those given by the pruned tree of possible futures. This, it seems to me, is the most natural way of understanding Subjective Possibilism within the most plausible Subjectivist moral framework extant, namely, the expected deontic value framework.

Return to the example illustrated in Figure 1 . If we assume that the option at node $d$ with the highest expected deontic value as of then is $d_{3}$ and the option at node $c$ with the highest expected deontic value as of then is $c_{2}$, then the resultant pruned tree of possible futures is illustrated in Figure 2. (The dashed lines in 
Figure 2 represent the branches of the original tree which have been "chopped off" in the pruning process.) From this pruned tree we can calculate the expected deontic value* for each of $S^{\prime}$ s two choices, $a_{1}$ and $a_{2}$ :

$$
\begin{aligned}
& \operatorname{EDV}^{*}\left(\mathrm{a}_{1}\right)=\mathrm{P}\left(\mathrm{b}_{1} \mid \mathrm{a}_{1}\right)\left(\mathrm{x}_{3}\right)+\mathrm{P}\left(\mathrm{b}_{2} \mid \mathrm{a}_{1}\right)\left(\mathrm{x}_{4}\right) \\
& \operatorname{EDV}^{*}\left(\mathrm{a}_{2}\right)=\mathrm{P}\left(\mathrm{f}_{1} \mid \mathrm{a}_{2} \& \mathrm{c}_{2}\right)\left(\mathrm{x}_{8}\right)+\mathrm{P}\left(\mathrm{f}_{2} \mid \mathrm{a}_{2} \& \mathrm{c}_{2}\right)\left(\mathrm{x}_{9}\right)
\end{aligned}
$$

And according to the Subjective Possibilist, whichever of $a_{1}$ and $a_{2} S$ ought to take will be determined by which of $\operatorname{EDV}^{*}\left(a_{1}\right)$ and $\operatorname{EDV}^{*}\left(a_{2}\right)$ is higher. (If $\operatorname{EDV}^{*}\left(a_{1}\right)=$ $\operatorname{EDV}^{*}\left(a_{2}\right)$ then both $a_{1}$ and $a_{2}$ are permissible.)

Though this is how Possibilism is best understood from within the most plausible Subjectivist moral framework, even so understood, Subjective Possibilism is highly implausible. To see why, consider the following case:

Liverwurst: $A, B$, and $C$ are drowning. At $t_{1}$, Ruiz can save $A$ or do nothing. If Ruiz saves $A$ at $t_{1}$, she will fall asleep between $t_{1}$ and $t_{2}$, and so though $A$ will live, $B$ and $C$ will both die. If Ruiz does nothing at $t_{1}$, then, at $t_{2}$, she will face a choice of ordering a liverwurst sandwich or not. At $t_{1}$, Ruiz knows the following five facts:

(1) if she saves $A$ at $t_{1}, B$ and $C$ will die,

(2) if after doing nothing at $t_{1}$ she chooses to order a liverwurst sandwich at $t_{2}$, some third party will save $A, B$, and $C$,

(3) if after doing nothing at $t_{1}$ she chooses to not order a liverwurst sandwich at $t_{2}, A, B$, and $C$ will all die,

(4) if she chooses to do nothing at $t_{1}$, between $t_{1}$ and $t_{2}$ she will forget both that $A, B$, and $C$ are drowning and that choosing to order a liverwurst sandwich at $t_{2}$ will result in their being saved from drowning, and

(5) if she chooses to do nothing at $t_{1}$, her hatred of liverwurst will persist from $t_{1}$ to $t_{2}$, and so, though she will be able to choose to order a liverwurst sandwich at $t_{2}$, the probability that she will then do so is 0.00000001 .

According to Subjective Possibilism, what Ruiz morally ought to do at $t_{1}$ in $\mathrm{Liv}$ erwurst is to do nothing. This is because the pruned tree of possible futures for her choice at $t_{1}$ consists of two non-forking branches on the first of which she saves $\mathrm{A}$ at $t_{1}$ but $\mathrm{B}$ and $\mathrm{C}$ both die, and on the second of which she does nothing at $t_{1}$ and orders a liverwurst sandwich at $t_{2}$ thereby unwittingly causing the saving A, B, and C. (The pruned tree of possible futures for Ruiz's choice at $t_{1}$ in Liverwurst is illustrated in Figure 3.) And this is because on the pruned tree of 


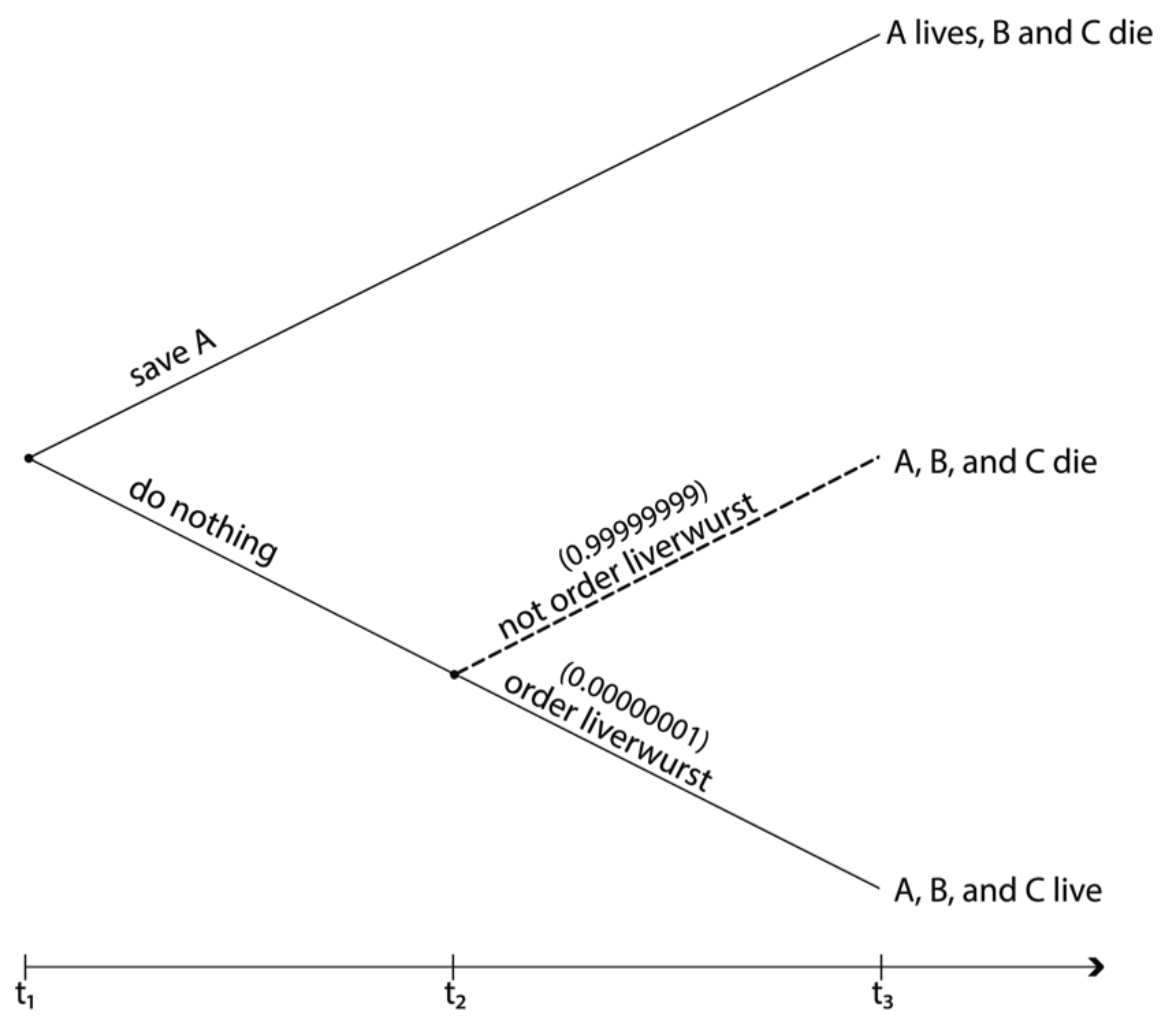

Figure 3

possible futures the branch where she fails to order the liverwurst sand wich at $t_{2}$ after doing nothing at $t_{1}$ is chopped off, for not ordering the liverwurst sandwich at $t_{2}$ after doing nothing at $t_{1}$ has a lower expected deontic value than does ordering it. So, according to Subjective Possibilism, choosing to do nothing at $t_{1}$ has the highest expected deontic value*, and so that is what Ruiz morally ought to do at $t_{1}$. I submit, however, that no one with Subjectivist sympathies will accept that what Ruiz morally ought to do at $t_{1}$ in Liverwurst is do nothing; anyone with Subjectivist sympathies will maintain that what Ruiz morally ought to do at $t_{1}$, given everything she knows then, is to save $A$.

Liverwurst highlights Subjective Possibilism's troubles with cases in which one's evidence changes over time. It can't deliver plausible verdicts about what an agent ought to do in such cases. And this is especially so when the agent knows in advance that her beliefs and evidence about the outcomes of her actions will be defective in the future. That Ruiz ought to do nothing at $t_{1}$ given everything she knows at that time in Liverwurst just seems untenable from the Subjectivist perspective. What's more, as Ruiz's future choice between ordering 
a liverwurst sandwich or not won't, according to the Subjectivist, be an occasion for her to comply with or flout the demands of morality-at the time of choice, from her perspective it will be a perfectly benign choice-the probabilities regarding how she would in fact choose, it seems, should matter, from any plausible Subjectivist perspective. Because behind Possibilism lies the thought that in terms of one's future actions one should behave in accord with the dictates of morality then, and cases like Liverwurst are ones in which one's future action doesn't stand a chance of flouting the dictates of morality from one's perspective then, given one's evidence of what one's evidence in the future will be, the evidence of how she will act in the future in such cases, it seems, should not be screened off. ${ }^{15}$

Now, it might seem that this problem for Subjective Possibilism is easily avoided. The problem arises because the pruning procedure as applied to Ruiz's choice at $t_{2}$ had it that ordering the liverwurst sandwich at $t_{2}$ has the highest expected deontic value* from then on. But that's true only in virtue of the evidence Ruiz has as of $t_{1}$ about what would happen were she to make whatever choice she might make at $t_{2}$. After Ruiz has forgotten about the three drowning individuals at $t_{2}$, however, Ruiz's evidence then, at $t_{2}$, indicates that ordering the liverwurst sandwich won't have the highest expected deontic value. Perhaps, it might be suggested, the Subjective Possibilist's pruning procedure should not be based on the evidence of the agent at the time of the choice with which the tree of possible futures is associated, namely, $t_{1}$, concerning the results of each of her possible choices at each point of pruning, but, rather, it should be based on the agent's evidence, at $t_{1}$, concerning what at each point of pruning her evidence then will be concerning the results of each of her various alternatives then. Maybe so modifying the pruning procedure will result in a version of Subjective Possibilism that evades the Liverwurst-based objection.

This proposed modification of the Subjective Possibilist pruning procedure won't do, however. Consider:

$\underline{\text { Insult: }} A, B$, and $C$ are drowning. At $t_{1}$, Nguyen can either sing a song or do nothing. If Nguyen sings a song at $t_{1}$, she will fall asleep between $t_{1}$ and $t_{2}$, and so $A, B$, and $C$ will all die. If she does nothing at $t_{1}$, then, at $t_{2}$, she'll face a choice whether to insult Mbeki's shoes, thereby causing

15. It is important to note here that though the verdict that Ruiz ought to do nothing at $t_{1}$ is one that no Subjectivist can accept, it is one that an Objectivist may well, and most certainly would, accept. Objectivists maintain, after all, that what we're morally required to do can be, and often is, outside our ken. Recall that the Objectivist holds that Chen is morally obliged to FLIP in Switch even though all her beliefs and evidence indicate that were she to FLIP her doing so would hurt no one and would also help Sanchez. There is thus no internal tension in combining Objectivism and Possibilism as there is in combining Subjectivism and Possibilism. 
Mbeki some mild distress, or not. At $t_{1}$, Nguyen knows the following five facts:

(1) if she sings a song at $t_{1}, A, B$, and $C$ will all die,

(2) if, after doing nothing at $t_{1}$, she does insult Mbeki's shoes at $t_{2}$, some third party will rescue all three of $A, B$, and $C$,

(3) if, after doing nothing at $t_{1}$, she does not insult Mbeki's shoes at $t_{2}$, then $A, B$, and $C$ will all drown,

(4) if she does nothing at $t_{1}$, between $t_{1}$ and $t_{2}$ she will forget both that $A, B$, and $C$ are drowning and that choosing to insult Mbeki's shoes at $t_{2}$ will result in their being saved from drowning, and

(5) if she does nothing at $t_{1}$, her hatred of Mbeki and her intense desire to insult Mbeki's shoes will persist from $t_{1}$ to $t_{2}$, and so, though she will be able to refrain from insulting Mbeki's shoes and causing Mbeki some mild distress at $t_{2}$, the probability that she will then insult Mbeki's shoes is 0.9999999 .

According to the proposed revision of Subjective Possibilism, it is permissible for Nguyen to sing a song at $t_{1}$. It will have this result because when pruning the tree of possible futures associated with Nguyen's choice at $t_{1}$, at $t_{2}$, the expected deontic value calculation as of $t_{2}$ is carried out not with respect to Nguyen's evidence at $t_{1}$ about what will happen were she to make whichever choice she makes at $t_{2}$, but, rather, with respect to Nguyen's evidence at $t_{1}$ about what her evidence at $t_{2}$ will be about what will happen were she to make whichever choice she makes at $t_{2}$. And with respect to that evidence, Nguyen's choosing not to insult Mbeki's shoes at $t_{2}$ will maximize expected deontic value* as of $t_{2}$; the evidence Nguyen knows at $t_{1}$ she will have at $t_{2}$ will indicate that insulting Mbeki's shoes will cause Mbeki some distress and benefit no one. But if that's the case, then the resulting pruned tree of possible futures for Nguyen's choice at $t_{1}$ will consist of the branch in which Nguyen sings a song at $t_{1}$ and the branch in which she does nothing at $t_{1}$ and does not insult Mbeki's shoes at $t_{2}$, both of which have the same expected deontic value ${ }^{*}$-both involve $A, B$, and $C$ dying. (The pruned tree of possible futures for Nguyen's choice at $t_{1}$ in Insult is illustrated in Figure 4.) And so, according to this revised version of Subjective Possibilism it is morally permissible for Nguyen to sing a song at $t_{1}$. I take it, however, that no Subjectivism worth its salt will have that consequence; anyone with Subjectivist sympathies will hold that what Nguyen morally ought to do at $t_{1}$, given everything she knows then, is do nothing. ${ }^{16}$

16. It won't do to suggest, as an anonymous referee does, that the Subjective Possibilist have it that an agent's obligations are determined by what is in the agent's epistemic ken at all moments together because, as what's in an agent's epistemic ken can change over time, such a body of evi- 


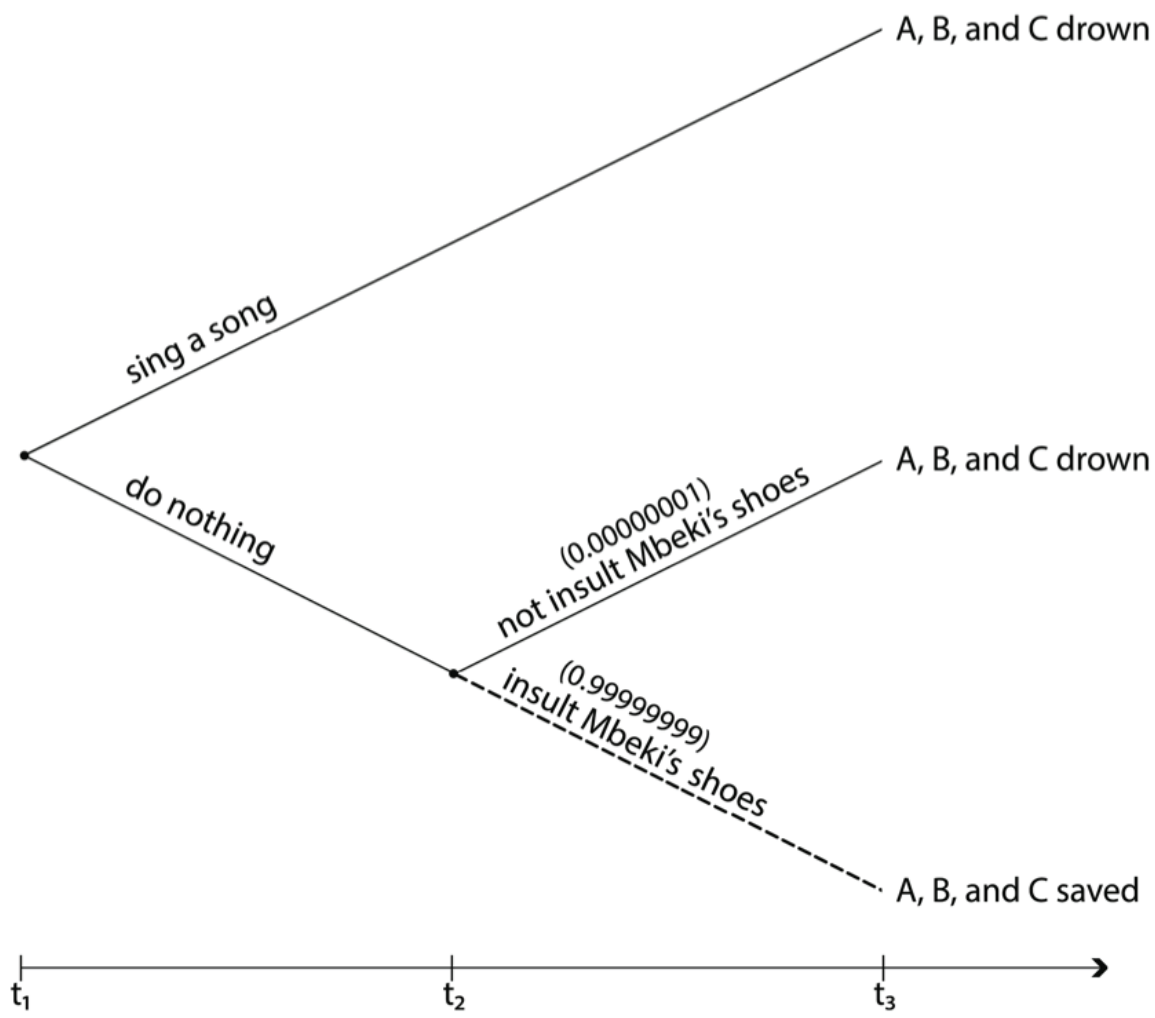

Figure 4

As I see no other plausible way of understanding Subjective Possibilism, and these ways of understanding it yield wildly implausible consequences by Subjectivism's own lights, if Subjectivism about moral obligation is true, then Subjective Actualism, and not Subjective Possibilism, must be correct. ${ }^{17,18}$

If all of this is right, then Subjectivism implies Actualism. In what follows, I argue that Actualism is false. If I establish this, I will thereby have established that the correct moral theory must be an Objective Possibilist one. (Unless otherwise indicated, in my argument against Actualism below I consider only situations in which the agents in question have full knowledge. So, I do not need to

dence may contain explicitly contradictory information and moral obligations most certainly can't be determined on the basis of an inconsistent set of propositions.

17. Liverwurst and Insult both also make trouble for the version of Subjective Possibilism Zimmerman (2008) puts forward.

18. Insofar as there are approaches to subjectivizing a moral theory that differ from the expected deontic value approach, my conclusion would have to be hedged: if some form of expected deontic value Subjectivism about moral obligation is true, then Subjective Actualism, and not Subjective Possibilism, must be correct. 
concern myself with the distinction between Objective Actualism and Subjective Actualism, for in cases of full knowledge the two theories are extensionally equivalent.)

\section{The Standard Challenge to Actualism and Actualist Replies}

The main Possibilist complaint against Actualism is straightforward: were Actualism true, one could get out of a present moral obligation simply in virtue of one's own potential future voluntary, and entirely avoidable, moral wrongdoing; "but that," so says the Possibilist, "just isn't how morality works". ${ }^{19}$ For example, if Actualism is true, Doctor can get out of having a moral obligation to give Patient drug D on Monday in Headache just because were she to do so, she'd later horribly wrongly allow Patient to die. But one can't just get off the moral hook in that way.

To this charge the Actualist has the following ready reply: yes, if Actualism is true, then one can indeed get out of having a moral obligation in virtue of one's own potential future moral failings, but that's only when and because those potential future moral failings would be so morally disastrous. What morality cannot allow is that one be morally required to act in some way at a time, $t$, that will lead to one's acting even more morally wrongly overall from $t$ onward than one would act by not doing what morality requires one to do at $t .^{20}$ The Possibilist fails to fully appreciate, says the Actualist, that allowing Doctor to GIVE D on Monday in Headache would be to allow her to do something that will lead to her acting horribly morally wrongly on Tuesday. And, what's more, letting Patient die on Tuesday after giving her D on Monday is far more seriously wrong than not relieving Patient of the five hours of excruciating pain on Monday were that what morality required. If morality could require people to do that which would lead them to act even more morally wrongly overall than not doing what it requires, morality would be seriously perverse. And morality is not perverse.

Furthermore, the Actualist might point out, no morally conscientious person would, were she in Doctor's shoes on Monday in Headache, Give D on Monday. ${ }^{21}$

19. See Zimmerman (1996) for an articulation of this objection.

20. Here I'm using 'lead to' in such a way that $S^{\prime}$ s $\phi$-ing will lead to $S^{\prime} s \psi$-ing just in case were $S$ to $\phi, S$ would $\psi$.

21. "Wait," you might protest. "A morally conscientious person would GIVE D on Monday in Headache. And that's because a morally conscientious person would GIVE D on Monday and then GIVE E on Tuesday in Headache." No. In replying on behalf of the Actualist here I am claiming that what it is morally conscientious for Doctor to do on Monday given her knowledge of how she will behave on Tuesday were she to GIVE D on Monday, is to GIVE D on Monday. And being morally conscientious on Monday given that particular knowledge does require doing GIVE D on Monday. Moral conscientiousness, as with all character traits, is a property of agents at times. Just as one 
Because one could indeed be a morally conscientious person on Monday and $\sim$ GIVE D then in Headache, then it must at least be permissible for Doctor to GIVE D in Headache, for no morally conscientious person would ever knowingly do what was morally wrong-moral conscientiousness precludes ever knowingly doing what is morally wrong. ${ }^{22}$ And because no person, were she being morally conscientious on Monday, given her knowledge of her own future potential morally unconscientious behavior, would GIVE D on Monday in Headache, then it must be that to GIVE D on Monday in Headache would be morally wrong, for if it weren't

can be honest at one time and then dishonest at a later time, and just as one can be rational at one time and then irrational at another, so too can one be morally conscientious at one time and then not morally conscientious at another. By way of analogy, take the case of rationality. Suppose I know that if I give you $\$ 1$ now, later both you will give me $\$ 5$ and I will then light that $\$ 5$ on fire for no apparent reason. In being in such a position, I know that if I give you $\$ 1$ now, I will be irrational in the future. Given that knowledge, the thing to do if I am rational now is to not give you my $\$ 1$. Knowledge of my potential future irrationality makes what it would be rational for me to do now different from what it would be were I to know that I wouldn't act irrationally in the future. Similarly, Doctor's knowledge of her own potential future moral unconscientiousness makes what it would be morally conscientious for her to do on Monday different from what it would be were she to know that she wouldn't act morally unconscientiously on Tuesday were she to GIVE D on Monday. So, just as questions can arise as to what it would be rational at one time to do in the face of knowledge of one's own future potential irrationality, so too can questions arise, as in Headache, as to what it would be morally conscientious to do at one time in the face of knowledge of one's own future potential moral unconscientiousness. My claim, which can be accepted by Actualists and Possibilists alike (see Footnote 5), is that being morally conscientious on Monday, in the face of knowledge of one's own potential future moral unconscientiousness, entails doing $\sim$ GIVE D. (Note: just as it doesn't follow from the fact that I will irrationally burn the $\$ 5$ were you to give it to me later that I am irrational now, before giving you my $\$_{1}$ (perhaps your giving me the $\$ 5$ is what causes my becoming irrational), it needn't follow from the set-up of Headache that Doctor is not morally conscientious on Monday. Furthermore, Doctor's potential future laziness on Tuesday, we might stipulate, has nothing to do with her present character traits and/or dispositions. Doctor's potential future laziness might be the result of some factor completely outside Doctor's control and something for which she would not be responsible. Perhaps, for instance, Doctor knows on Monday that she'll lazily not GIVE e on Tuesday if she does gIVE D on Monday only because she knows that after doing GIVE D on Monday some third party will inject her with a powerful laziness-inducing drug. (Vessel, 2015, assumes that if it is true that I would fail to GIVE E on Tuesday after doing GIVE D on Monday in this latter type of case, then it follows from that that I am vicious on Monday. This is a mistaken account of vice, however-according to it, correctly, a vice is a disposition to behave in certain ways, and, incorrectly, the mere holding of the counterfactual that I wouldn't GIVE E on Tuesday were I to GIVE D on Monday is sufficient for my on Monday being disposed to GIVE E on Tuesday were I to GIVE D on Monday. The latter is a mistaken view of dispositions. Surely dispositions can be gained and lost, and we can suppose that in the case just described it is a feature of the laziness-inducing drug that it gives me the disposition to GIVE E on Tuesday, not that I had that disposition to GIVE E on Tuesday were I to GIVE D on Monday prior to being given the drug. On the other hand, if I am wrong about this, and Vessel is right, then so much the worse for the Actualist, for in that case she cannot appeal to considerations of what the morally conscientious person would do in Headache to defend her view of what Doctor is morally obliged to do against the Possibilist critique of it.))

22. Zimmerman (2008) endorses this claim about moral conscientiousness. It is not entirely uncontroversial, however; Bykvist (2009) and Graham (2010) reject it. 
it would have to be possible for someone who was being morally conscientious then to do so.

The Possibilist attack upon Actualism, then, can be blunted, it might be thought, by appeal (1) to the non-perversity of morality, and (2) to the extensional equivalence of the morally required and that which no morally conscientious person would knowingly fail to do.

\section{Actualism's Difficulties with Beneficial Sacrifice}

The Actualist may indeed have a passable reply to the charge that Actualism implausibly allows people to get out of having certain present moral obligations simply in virtue of their potential future moral failings. Possibilism is most certainly not the dominant view. In fact, the Actualism/Possibilism debate has settled into a seemingly intractable stalemate. I hope to break through this stalemate. I argue that Actualism has difficulties with a particular moral phenomenon, one I call "permissible beneficial sacrifice", difficulties which cannot be circumvented by the kinds of replies Actualists offer in response to the standard challenge to Actualism. First, I distinguish between the two dominant versions of Actualism currently in play, and then I show how they each run into trouble in cases of permissible beneficial sacrifice.

\subsection{Two Actualisms}

There are two main versions of Actualism. Both have at their core the following thesis about moral permissibility:

\section{Actualism Core (AC)}

It is permissible for $S$ to $\phi$ from $t_{1}-t_{2}$ just in case (1) $S$ is able, at $t_{1}$, to $\phi$ from $t_{1}-t_{2}, 23,24$ and (2) there is no possible world that would be actual were $S$ to do,

23. I assume (1) that abilities are held at times and (2) that abilities are abilities to perform actions at times (in which case $t_{1}=t_{2}$ and the $\phi$-ing is said to be performed 'at $t_{1}$ ') or abilities to perform actions or series of actions across time (in which case $t_{1}<t_{2}$ ).

24. Doubly time-indexed ability claims - the first index indicating the time at which the ability is had and the second indicating the time of the performance of the action the ability is an ability to perform - such as those in $A C$, are, to be sure, not bits of ordinary, everyday English. Rarely, if ever, would one say that one can now do something tomorrow. We do often talk, however, of our abilities to perform courses of action or series of actions over periods of time. Doubly time-indexed ability claims are just one precisifying regimentation of this talk of our abilities to perform various courses of action over time. To say that one is able now to $\phi$ later is just to say that there is a course of action (perhaps including doing nothing at various points) one now has the ability to perform such that were one to perform it, one would $\phi$ later in the course of one's performance of it. 
from $t_{1}-t_{2}$, anything other than $\phi$ that $S$ is able, at $t_{1}$, to do from $t_{1}-t_{2}$ which has a higher deontic value for $S$ at $t_{1}{ }^{25}$ than does the possible world that would be actual were $S$ to $\phi$ from $t_{1}-t_{2}$.

Where the two versions of Actualism diverge is in their respective accounts of the notion of ability appealed to in $A C$. According to the first, what an agent is able to do at $t_{1}$ are all the actions and series of actions that she would perform were she to do each of the things she is able, at $t_{1}$, to do at $t_{1}$. According to the second version of Actualism, what an agent is able to do at $t_{1}$ are all the actions and series of actions that she would perform were she to do each of the things she is able, at $t_{1}$, to do at $t_{1}$ and also all of the actions and series of actions she would later be able to perform were she to do each of those things. ${ }^{26}$ More precisely, the account of ability appealed to in $A C$ according to the first version of Actualism is:

Able(1): $S$ is able, at $t_{1}$, to $\phi$ from $t_{1}-t_{2}$ iff there is some $\psi$ such that

(i) $S$ is able, at $t_{1}$, to $\psi$ at $t_{1}$, and

(ii) were $S$ to $\psi$ at $t_{1}$, it would be the case that $S \phi$ s at $t_{2}$.

And the account of ability appealed to in $A C$ according to the second version of Actualism is:

25. Once again, by the 'deontic value of a possible world, $w$, for $S$ at $t_{1}^{\prime}$ I mean the cardinalization of the ranking, out of all the possible worlds the agent could at $t_{1}$ make actual by performing the actions she could then perform, that whatever the correct moral theory happens to be assigns to $w$ for $S$ at $t_{1}$. Whether consequentialist or not, given a slate of actions available to an agent at a time, the correct moral theory assigns not merely the properties of rightness and wrongness but also a relative moral ranking to those various actions (each action associated with a possible world (or set of possible worlds) that would be actual (that might be actual) were that action performed). Some actions are more wrong than others: my pinching my spouse in the arm, for instance, is wrong, but my cheating on him behind his back is (much!) more wrong. What's more, the cardinalization assumption does not seem unwarranted, for not only is cheating on my spouse more wrong than is pinching him, it seems clearly more than twice as wrong as pinching him is. The cardinalization assumption, once again, is indeed crucial to the expected deontic value approach I pursued in Section 3 . And though there clearly are epistemic limitations to a precise estimation of these deontic values, there is reason to believe that there are, in principle, numerical values which the correct moral theory assigns to the possible worlds associated with the alternatives available to an agent at a time.

26. Another way of understanding these two notions of cross-temporal ability claims is as two different conceptions of what a person's "diachronic options" at a time are. Jackson and Pargetter (1986) cast the difference in terms of 'options' instead of the kinds of cross-temporal ability claims I employ here. These are mere notational variants of one another.

Ergo • vol. 6, no. 8 • 2019 
Able(2): $S$ is able, at $t_{1}$, to $\phi$ from $t_{1}-t_{2}$ iff there is some $\psi$ such that

(i) $S$ is able, at $t_{1}$, to $\psi$ at $t_{1}$, and

(ii) were $S$ to $\psi$ at $t_{1}$, it would be the case that $S$ is able, at $t_{2}$, to $\phi$ at $t_{2} \cdot{ }^{27}$

Henceforth, let 'able ${ }_{1}$ ' refer to the notion given by $\mathbf{A b l e ( 1 )}$ and let 'able ${ }_{2}$ ' refer to that given by Able(2). The first version of Actualism, Actualism 1, is that which is gotten by replacing all occurrences of 'able' in $A C$ with 'able ${ }_{1}$ ', and the second version of Actualism, Actualism 2, is that which is gotten be replacing all such occurrences with ' $\mathrm{able}_{2}$ '. ${ }^{28,29}$

Consider Headache once again. Here are the relevant ability data in that case:

On Monday, Doctor is both able ${ }_{1}$ and able $_{2}$ either to GIVE D or to GIVE D on Monday.

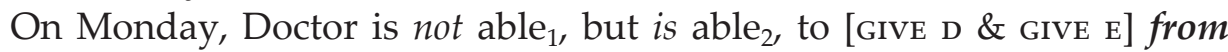
Monday to Tuesday.

Given these data, Actualism 1 and Actualism 2 agree about what it is permissible for Doctor to do on Monday-namely, GIVE D, and only GIVE D. But they disagree about what it is permissible for Doctor to do from Monday to Tues-

27. Well, not quite. Though Able(2) gives the sense of the notion of ability the second kind of Actualist has in mind, an even more precise formulation of it would go something like:

Able(2)': $S$ is able, at $t_{1}$, to $\phi$ from $t_{1}-t_{2}$ iff there is some ordered series of compossible act tokens $<\psi_{1}, \ldots, \psi_{n}>$ such that

(i) $S$ is able, at $t_{1}$, to $\psi_{1}$ at $t_{1}$,

(ii) were $S$ to perform $\left\langle\psi_{1}, \ldots, \psi_{n}>\right.$, it would be the case that $S$ is able, at $t_{2}$, to $\phi$ at $t_{2}$.

(iii) for each nesting subseries, $\left\langle\psi_{1}, \ldots, \psi_{i+1}\right\rangle$, of $\left\langle\psi_{1}, \ldots, \psi_{n}\right\rangle$, were $S$ to perform $\psi_{1} \& \ldots$ $\& \psi_{i}$, it would be the case that $S$ is able, at $t_{i+1}$, to $\psi_{i+1}$ at $t_{i+1}$.

28. Portmore (2011) is a proponent of (a version) of Actualism 1 and Jackson and Pargetter (1986) are proponents of Actualism 2.

29. Jacob Ross maintains that "what is obligatory for an agent is that, (i) at all times, she does (ii) the best she can do at that time, (iii) holding fixed what is not up to her at that time, but (iv) not holding fixed what is up to her at that time" (2012: 89). The dispute between the Possibilist and the proponent of Actualism 1 just is a dispute about what counts as being "up to the agent" at a time. The proponent of Actualism 1 thinks that only the things a person is able ${ }_{1}$ to do at a time are up to her, in the relevant sense, at that time. The Possibilist, on the other hand, thinks that what a person is able ${ }_{2}$ to do at a time are up to her, in the relevant sense, at that time. The dispute between the Possibilist and the proponent of Actualism 2 is not a dispute about what is up to an agent at a time because they both agree that what is up to an agent in the relevant sense at a time is what she is able ${ }_{2}$ to do at that time. Rather the dispute here is about whether the only things we hold fixed in determining what an agent ought to do are those things which are not up to the agent at that time. According to Actualism 2 what we hold fixed includes more than what is not up to the agent at that time; according to Actualism 2 we also hold fixed what the agent will do in the future even if what the agent will do in the future is something that is up to the agent in the relevant sense at that time. For the Possibilist, we hold fixed only what is not up to the agent at the relevant time, i.e., those things she is not able to $_{2}$ affect. 
day. Actualism 1 dictates that it is permissible only for Doctor to [ GIVE D \& GIVE

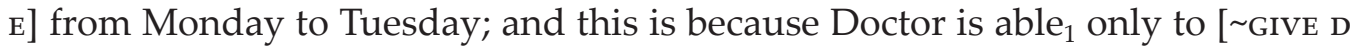
\& $\sim$ GIVE E] or to [GIVE D \& GIVE E] from Monday to Tuesday, and of those two options [ GIVE D \& $\sim$ GIVE E] is clearly best. Actualism 2 dictates that it is permissible only for Doctor to [GIVE D \& GIVE E] from Monday to Tuesday; and this is because Doctor is able $_{2}$ to [GIVE D \& GIVE E] from Monday to Tuesday and that is clearly her best option from Monday to Tuesday.

Because Actualism 2 has it that Doctor both is not morally obliged to GIVE D on Monday and also is morally obliged to [Give D \& GIVE E] from Monday to Tuesday it is thus committed to rejecting a popular deontic principle:

'And'-Elimination for Moral Obligation (AEMO): Necessarily, if $S$ is morally obliged to $(\phi \& \psi)$ from $t_{\phi}-t_{\psi}\left(t_{\phi} \leq t_{\psi}\right)$, and $S$ can, at $t_{\phi} \phi$ at $t_{\phi}$ then $S$ is morally obliged to $\phi$ at $t_{\phi} \cdot{ }^{30}$

To many, this is a huge cost; it seems counterintuitive that one could be obliged to carry out some course of action but not also be obliged to do that which is the necessary first step of carrying it out. Many find the cost of giving up AEMO so great as to render Actualism 2 a non-starter. (I side with the too-great-a-cost camp.) However, one benefit of Actualism 2, it might be suggested, is that it allows us to say that though it would be morally impermissible for Doctor to GIVE D on Monday, nevertheless, if Doctor does GIVE D on Monday, that will entail her failing to [GIVE D \& GIVE E] from Monday to Tuesday, thereby falling short of fulfilling all of her moral obligations. ${ }^{31}$ And there does seem to be something morally deficient in Doctor when she fails to give Patient drug D on Monday in Headache. She's knowingly refraining from performing the course of action which would completely cure Patient.

This purported benefit of Actualism 2 over Actualism 1 is a mirage. Any intuitive thought of Doctor's exhibiting a moral failing in Headache can be easily accounted for by the proponent of Actualism 1 by noting that Doctor, in virtue of her current disposition to fail to act on Tuesday, is seriously morally deficient. (This is important because, for there to be a sense of moral failing on the part of Doctor on Monday, the proponent of Actualism 1 can plausibly maintain, her potential future failure to act must reflect something about Doctor's character on Monday. Were she not disposed on Monday to not administer E on Tuesday, then there wouldn't be any intuitive sense of moral failing on the part of Doctor

30. Neither Actualism 1 nor Possibilism is committed to denying this principle.

31. Some proponents of Actualism 2, Jackson and Pargetter (1986) for instance, suggest this as an attractive feature of their view. 
on Monday in need of being given an account of..$^{32}$ ) Being disposed not to do that which one could easily do to save someone else's life is a serious moral character flaw. What's more, this explanation may well be better than that offered by the proponent of Actualism 2. For in versions of Headache in which Doctor's potential future failure to administer E would not be caused by a moral character flaw, Actualism 1 needn't provide grounds for any intuitive thought that there is any such moral failing.

Headache (Switched Labels): Everything is as it is in Headache except that were Doctor to administer D on Monday, she would fail to administer E on Tuesday, not because of her own potential future laziness, but because she knows, on Monday, that on Tuesday the labels on the drugs, unbeknownst to her then, will have been switched around (the result of the dastardly behavior of some evil third party). Doctor does not administer D on Monday.

Here, it may seem, there isn't any moral failing on Doctor's part that needs accounting for at all, and yet the proponent of Actualism 2 is committed to the claim that in doing GIVE D on Monday, Doctor fails to carry out one of her obligations, namely, to [GIVE D \& GIVE E] from Monday to Tuesday. And she claims that that kind of failure grounds an intuitive thought that there is some moral failing exemplified in Doctor's doing GIVE D on Monday in Headache. But, and here's the problem, there is no such intuitive thought regarding Headache (Switched Labels).33

None of this is to say, of course, that Actualism 2 doesn't have advantages over Actualism 1. It's only to say that its being able to accommodate a certain sense that there is some moral failing associated with Doctor's doing GIVE D on Monday in Headache isn't one of them. Though I do not think Actualism 2 has any advantages over Actualism 1, and Actualism 1 has the merit of not entailing the falsity of AEMO, both versions of Actualism have serious problems with merely permissible beneficial sacrifice.

32. I am thus assuming that Headache here is not like the version of that case involving the laziness-inducing drug I describe in Footnote 21.

33. Epistemic cases, like Headache (Switched Labels), are conspicuously absent in discussions of the Actualism/Possibilism debate. And it is only because of their absence, I maintain, that the purported benefit of Actualism 2 which I discuss here can at all seem to be a benefit. Even the most cursory reflection upon epistemic cases like Headache (Switched Labels) show definitively that the purported benefit of Actualism 2 over Actualism 1 is a mere phantom. Also, though epistemic cases most vividly show this, non-epistemic versions of Headache, like that described in Footnote 21, can be constructed which equally well establish that Actualism 2 does not have the kind of advantage over Actualism 1 that the purported benefit claims it has. 


\subsection{Actualism and Beneficial Sacrifice}

Having thus distinguished the two main versions of Actualism, I now show how they each have trouble with merely permissible beneficial sacrifice.

First, a couple words about beneficial sacrifice. By 'beneficial sacrifice' I mean any action whereby the agent imposes a loss upon, or allows a loss to befall, someoneeither the agent herself (an instance of beneficial self-sacrifice) or someone else (an instance of beneficial other-sacrifice) - in order to prevent yet others from suffering a loss. Some beneficial sacrifice is morally required. If I can save an innocent person from drowning but only by doing something that will cause me, or even you, a two-hour headache, then I'm morally required to save the person and cause the headache. Some beneficial sacrifice is morally impermissible, of course-as when I kill you in order to prevent someone else from suffering a two-hour headache. And, finally, some beneficial sacrifice is neither impermissible nor morally required, it is merely morally permissible. If I can save a person from drowning, but only at the cost of my own life, then I'm morally permitted, though not required, to sacrifice my life to save the person. And if I can save a person from drowning, but only by doing something that will cause you the loss of two fingers, then I'm morally permitted, though not required, to save the person at the cost to you of your two fingers. 34

Merely permissible beneficial sacrifice makes trouble for both versions of Actualism. I begin by considering their troubles with merely permissible beneficial self-sacrifice. ${ }^{35}$ Not only do both versions of Actualism allow people to get out of having certain present moral obligations in virtue of their potential future moral failings, they also, much more troublingly, allow people to get out of having certain present moral obligations in virtue of their potential future morally supererogatory behavior.

Take Actualism 1 first and consider the following case involving diachronic supererogation:

Three Drowning: Chang stands at the edge of a pond in which three people are drowning. At $t_{1}$, Chang's options are:

DIVE: dive in and save two of the three

$\sim$ DIVE: not dive in and allow all three to drown

34. Note the important asymmetry: other things being equal, whereas I am permitted to impose upon myself losses as great as, and in some cases even greater than, the loss prevented in preventing a loss, I'm often (if not always) not permitted to impose upon someone else losses as great as, and certainly not greater than, the loss prevented in preventing that loss.

35. Certain Consequentialists, in particular, Consequentialists who reject the possibility of supererogation, may not be moved by my arguments in this section. This is not a problem for my argument, however, for the possibility of supererogation is quite intuitive and thus my argument establishes that Actualism is false for any moral theory which hews even somewhat closely to ordinary commonsense morality. 
If Chang were to DIVE at $t_{1}$, then her options at $t_{2}$ would be:

STAY: stay in the pond and save the remaining person at the cost of her leg (a crocodile would bite off Chang's leg if she stays and saves the one)

EXIT: exit the pond, thereby allowing the remaining person to drown and not losing a leg

Chang knows at $t_{1}$ that if she were to Dive at $t_{1}$, then, though she would be able to EXIT at $t_{2}$, because she would then be so committed to saving as many people as she can, she would freely (non-pathologically, noncompulsively, etc.) and fully-informedly choose to STAY, thereby saving the remaining person and losing her leg. (Chang also knows at $t_{1}$ that if she were to $\sim$ DIVE at $t_{1}$, then at no time after $t_{1}$ would she be able to save any of the three, and so all three would drown.)

In Three Drowning the relevant ability data are:

At $t_{1}$, Chang is both able $e_{1}$ and able $_{2}$ either to DIVE or to $\sim$ DIVE $a t t_{1}$. At $t_{1}$, Chang is not able ${ }_{1}$, but is able , $_{2}$ to [DIVE \& EXIT] from $\boldsymbol{t}_{1}$ to $\boldsymbol{t}_{2}$.

Because at $t_{1}$ Chang is only able ${ }_{1}$ to DIVE or $\sim$ DIVE at $t_{1}$, Actualism 1 deems it morally permissible for Chang to $\sim$ DIvE at $t_{1}$ in Three Drowning. And that's because were Chang to DIVE at $t_{1}$ she would sTAY at $t_{2}$, thereby losing a leg and saving three people, and no one is morally required to lose a leg in order to save one or even three people from drowning. ${ }^{6}$ But it is not morally permissible for Chang to $\sim$ DIVE at $t_{1}$ in Three Drowning. Chang is not permitted, for any ordinary and intuitive sense of 'permitted', to allow the two people she could easily save, at no cost to herself, from drowning at $t_{1}$ to drown.

It is important to keep in mind when considering Three Drowning that Chang's potential future rescuing of the third person at the cost of her leg at $t_{2}$ were she to DIVE at $t_{1}$ is something that she would freely, uncoercedly, and uncompelledly do at $t_{2}$. Chang's knowledge that she would do this were she to DIVE at $t_{1}$ is just the everyday, ordinary kind of knowledge that a procrastinator has of her own future voluntary procrastination; the procrastinator knows ahead of time that she will freely, uncoercedly, and uncompelledly procrastinate in the future. ${ }^{37}$ We mustn't think that because Chang knows that she will come to want, and act so as, to save as many people as she can at $t_{2}$ were she to DIVE at

36. I'm stipulating this for the purposes of this argument. All the argument needs is some level of self-sacrifice that is permissible but not required in order to save three innocent people.

37. Jackson and Pargetter's (1986) example of Professor Procrastinate is an important point of comparison here. It is crucial to their case that Professor Procrastinate knows ahead of time both 
$t_{1}$ that this means that there is any sense in which at $t_{1}$ she is already committed to or in the grip of some general deep standing commitment to save as many people as she can. Again, she simply knows, perhaps from past experience - just as the procrastinator can know of her potential future procrastination from past experience - that she will end up going above and beyond the call of duty and saving the third person at the cost of her leg at $t_{2}$ were she to DIVE at $t_{1}$. All the same, the fact that she knows this in no way makes it okay now for her to fail to rescue the two she could easily save at $t_{1}$.

In response to all of this the proponent of Actualism 1 might suggest that its being permissible for Chang to $\sim$ DIVE at $t_{1}$ isn't actually counterintuitive at all. After all, she might say, there is nothing Chang is able at $\mathrm{t}_{1}$ to do such that were she to do it she would rescue the two without losing her leg, and no one is morally obliged to lose a leg in order to save two, or even three, people from drowning. Here the proponent of Actualism 1 is leaning heavily on the thought that, given the set-up of the case, Chang simply can't, she's simply unable to, rescue the two without losing her leg. But that's just to assume that Able(1), instead of Able(2), is the morally relevant notion of cross-temporal ability, and that's precisely what's at issue between Actualism 1 and Possibilism. ${ }^{38}$ If Able(2) is the morally relevant notion of cross-temporal ability, then Chang is able at $t_{1}$, in the morally relevant sense of 'able', to rescue the two without losing her leg. To adjudicate between Possibilism and Actualism 1, then, we need to approach Three Drowning without assuming either Able(1) or Able(2) is the morally relevant notion of cross-temporal ability. Once we do this, however, the proponent of Actualism 1's case for the permissibility of Chang's not diving in and saving the two at $t_{1}$ falls apart.

Consider the following conversation between Chang and Torres, an onlooker, after Chang refrains from diving in and saving the two at $t_{1}$ :

Torres: Why didn't you dive in and save those two people?!

Chang: It was okay for me not to.

Torres: What?! Of course it wasn't okay. You could have dived in and then you could have easily lifted them out.

Chang: No. You see there's a crocodile in there and if I saved them it would've bitten my leg off.

Torres: I see. If you jumped in and saved them you'd not have been able to avoid losing your leg.

Chang: Oh no. I didn't say that. If I had dived in and saved them I would

that he will procrastinate in the future if he accepts the assignment and that that future procrastination will be something which is completely up to him when he procrastinates.

38. See Footnote 29. 
have quite easily been able to get out without losing my leg. It's just that I know myself: if I had dived in, I would have chosen to stay in and because of that choice I would make, the crocodile would bite my leg off.

Chang's explanation of why she's permitted to let the two people drown falls flat. Her defense would be a lot stronger if she could somehow sneak in that she can't save the two without losing her leg. But, again, that would simply be assuming that Able(1), and not Able(2), is the morally relevant notion of crosstemporal ability, something to which, in this dialectical context, she is not entitled. 39 Shorn of an appeal to inability, Chang's defense of her not saving the two crumbles. And that it crumbles puts the lie to the proponent of Actualism 1's claim that its being permissible for Chang to $\sim$ DIVE at $t_{1}$ isn't counterintuitive.

Three Drowning poses a more severe problem for Actualism 1 than that posed by Headache. In Headache, the proponent of Actualism 1 can support her claim that Doctor is not morally required to GIVE D on Monday in Headache by pointing to the fact that were she to GIVE D on Monday, that would lead to her acting more morally wrongly overall than she would were she to $\sim$ GIVE D on the supposition that GIVE D is required. Nothing like this is available to the proponent of Actualism 1 to explain how Chang could be permitted not to save the two people she could easily save at $t_{1}$ in Three Drowning. If she can easily save the two at $t_{1}$ and afterwards easily avoid any injury to herself by getting out of the pond, which it would then be perfectly permissible for her to do, how could she possibly be permitted to not save the two at $t_{1}$ ? Likewise, in Headache, the fact that no person who is being morally conscientious on Monday in Headache would GIVE D on Monday might support the Actualist's claim that in Headache it is morally impermissible for Doctor to GIVE D on Monday. But if that's so, then the fact that no morally conscientious person would fail to dive in and save the two at $t_{1}$ in Three Drowning - as no morally conscientious person would fail to do-should also establish that it is morally impermissible, and not permissible, as Actualism 1 dictates, for Chang to $\sim$ DIvE at $t_{1}$ in Three Drowning. None of the defenses proponents of Actualism offer up in response to the kinds of Headache-based criticisms leveled against it are available in response to the Three Drowning-based objection to Actualism 1.

39. Importantly, nowhere in the above dialogue does Torres assume that Able(2) is the morally relevant notion of cross-temporal ability. None of Torres's claims about what Chang is able to do is tendentious: all of Torres's claims about what Chang is able to do are synchronic 'able'claims, claims none of which are in dispute between the Possibilist and the proponent of Actualism 1. That the case for Actualism 1's verdict falls apart once the facts of the case are presented independent of a commitment to the moral relevance of one particular conception of cross-temporal ability over the other actually supports the Possibilist's contention that it is Able(2), in fact, which is the morally relevant notion of cross-temporal ability. 
Actualism 2 might seem to be able to avoid the problem posed by Three Drowning. Like Actualism 1, and for the very same reason, Actualism 2 has the consequence that it is morally permissible for Chang to $\sim$ DIVE at $t_{1}$. However, unlike Actualism 1, Actualism 2 also has the consequence that it is not morally permissible for Chang to $\sim$ DIVE from $t_{1}$ to $t_{2} .^{40}$ That's because Chang is able ${ }_{2}$, at $t_{1}$, to [DIVE \& EXIT] from $t_{1}$ to $t_{2}$ and if one can [DIVE \& EXIT], instead of $\sim$ DIVE, from $t_{1}$ to $t_{2}$, one morally ought not to $\sim$ DIVE from $t_{1}$ to $t_{2}$. (Actualism 1 does not have this consequence because Chang is not able ${ }_{1}$, at $t_{1}$, to [DIVE \& EXIT] from $t_{1}$ to $t_{2}$ in Three Drowning.) Actualism 2, then, may be thought to have resources Actualism 1 lacks in responding to the Three Drowning-based objection. Though Actualism 2 does yield that it is permissible for Chang to $\sim$ DIVE at $t_{1}$, it can nonetheless offer a relatively straightforward error theory for the thought that it is impermissible for Chang to $\sim$ DIVE at $t_{1}$ : it seems impermissible for Chang to $\sim$ DIVE at $t_{1}$, the proponent of Actualism 2 might contend, because there is something close to it, namely, Chang's doing DIVE from $t_{1}$ to $t_{2}$, which is impermissible for Chang. Mightn't this allow Actualism 2 to avoid the objection from supererogation?

No. What is objectionable about Actualism 1 is not merely that it can't somehow account for the thought that it is morally impermissible for Chang to allow the two people she could save to drown, it's that it allows that there is a sense in which it is permissible for Chang to let them drown. Intuitively, however, there is no sense in which it is permissible-morally ok, morally allowed, morally fine, etc. - for Chang to let the two she is able (both able ${ }_{1}$ and $a_{b l e}$ ) to easily save drown. Since Actualism 2 has this consequence, the Three Drowning-based objection tells against Actualism 2 just as much as it does against Actualism 1. ${ }^{41}$

40. I write ' $\sim$ DIVE from $t_{1}$ to $t_{2}$ ' instead of '[ $\sim$ DIVE \& NOTHING] from $t_{1}$ to $t_{2}$ ' merely for ease of presentation. Because she'll not be able (in any sense of 'able') to do anything at $t_{2}$ if she does $\sim$ DIVE at $t_{1}$, necessarily, if she does $\sim$ DIVE at $t_{1}$, then she will do [ DIVE \& NOTHING] from $t_{1}$ to $t_{2}$.

41. An anonymous referee suggests that Possibilism has its own serious problem with supererogation and so even if Actualism also has problems with supererogation, that needn't give us sufficient reason to abandon it. Possibilism's apparent troubles with supererogation arise in cases like the following:

Button: Ito is about to fall and break his leg. The Devil presents Tran with a button and says, "If you push this button at $t_{1}$, I will prevent Ito from breaking his leg; but if you push the button at $t_{1}$ and then freely perform one wrong action (no matter how trivial) for the rest of your (80-year) life, you will be tortured for 1000 years."

The problem for Possibilism is that, plausibly, Tran is not morally obligated to push the button in Button, but it can seem hard to see how Possibilism can deliver this verdict. Tran can, after all, prevent Ito's breaking his leg while at the same time not being tortured for 1000 years, and so, from the Possibilist point of view, if she can do those things, then presumably she is morally obliged to push the button. Appearances notwithstanding, Button does not pose a problem for Possibilism, and that's because it can in fact deliver the verdict that Tran is not morally obligated to push the button. What Button does show, I believe, is only that the moral permissibility of an agent's action may indeed partly supervene on her subjective state. (Note that this is consistent 
Actualism has trouble not only with merely permissible beneficial selfsacrifice, but with merely permissible beneficial other-sacrifice as well. Consider the following case:

Trolley: Six people are trapped on a track along which an out-of-control trolley is hurtling. At $t_{1}$, a bystander, Khan, has two options:

PULL: pull four of the six off the track, thereby saving them

PULL: not pull the four off the track, thereby allowing all six to be run over and killed

If Khan were to PULL at $t_{1}$, her doing so would enable her at $t_{2}$ to flip a switch which would turn the trolley away from the remaining two and onto a side-spur of track on which one other innocent person is trapped. (If she doesn't pull at $t_{1}$ she won't be able to flip the switch at $t_{2}$ because the four would be standing in the way of her reaching the switch.) And so, if Khan were to PULL at $t_{1}$, her options at $t_{2}$ would be:

TURN: turn the trolley away from the remaining two, thereby saving them, and onto the one, thereby killing him

$\sim$ TURN: not turn the trolley, thereby allowing it to run over the remaining two and not killing the one

with my definition of Objectivism; see Footnote 4.) What makes it the case that Tran is not morally obligated to push the button at $t_{1}$ in Button is that the harm of suffering 1000 years of torture is not morally relevantly avoidable for her at $t_{1}$. Morally relevantly avoidable harm clearly has a subjective component: if you throw a baseball at the back of my head, though I could have avoided it by stepping aside at the moment it was about to hit me, because I had no idea that you were throwing it at me, when it hit me in the back of the head, that harm was not a morally relevantly avoidable one for me. So too, though there is some precise sequence of actions Tran could take after pressing the button such that she would be able to avoid being tortured for 1000 years were she to push the button and then perform that sequence of actions, because she wouldn't know at every moment throughout her 80-year life how she'd have to behave to avoid being tortured for 1000 years, the torture were she to suffer it would not be morally relevantly avoidable for her when she suffers it. (Were it stipulated, on the other hand, that she knew at $t_{1}$ that at every moment in her life she would be aware of which choice would lead to her being tortured for 1000 years, then though the Possibilist would then have to say that she is morally obliged to push the button at $t_{1}$, that would be the intuitive verdict in such a case.) And as she is morally obligated to save Ito from suffering a broken leg at $t_{1}$ only if any harm greater than that which would be supererogatory for preventing a broken leg she might suffer in preventing it is such that were she to prevent Ito's breaking his leg either she wouldn't suffer it or her suffering it would have been morally relevantly avoidable for her when she suffered it, it is not the case, even for the Possibilist, that Tran is morally obligated to push the button at $t_{1}$ in Button. That it is the subjective nature of the avoidability of the harm in question which is at the root of Tran's not being morally obligated to push the button can be seen by noticing that if in Button it were in addition stipulated that Tran knows at $t_{1}$ that were she to press the button she in fact wouldn't perform a morally wrong action throughout the rest of her 80year life, then, intuitively, it would be the case that she is morally obligated to push the button at $t_{1}$. 
Khan knows at $t_{1}$ that if she were to PULL at $t_{1}$, then, though she would be able to $\sim$ TURN at $t_{2}$, because she would then be so committed to saving as many people as she can, she would freely (non-pathologically, noncompulsively, etc.) and fully-informedly choose to TURN, thereby saving the remaining two and killing the one.

In Trolley the relevant ability data are:

At $t_{1}$, Khan is both able ${ }_{1}$ and able either to PULL or to $\sim$ PULL $a t t_{1}$.

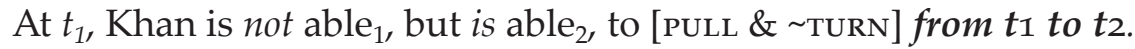

Because Khan is only able (both able ${ }_{1}$ and able 2 ), at $t_{1}$, to PULL or $\sim$ PULL at $t_{1}$, both Actualism 1 and Actualism 2 deem it morally permissible for Khan to $\sim$ PULL at $t_{1}$ in Trolley. And that's because were Khan to PULL at $t_{1}$ she would TURN at $t_{2}$, thereby killing an innocent person and saving six people. And though it is permissible to kill one in redirecting a threat away from two, it is not morally required to kill an innocent person, whether by redirection or not, in order to save two, or even six, people from being killed..$^{2}$ But it is not morally permissible for Khan to $\sim$ PULL at $t_{1}$ in Trolley. It is very seriously morally wrong for her to allow the four people she could easily pull off the track at $t_{1}$ to be run over and killed by the trolley. (Actualism 2 also has the consequence that it is not morally permissible for Khan to $\sim$ PULL from $t_{1}$ to $t_{2}$ in Trolley. ${ }^{43}$ But, as before, this is no saving grace, for allowing that there is some intuitive sense in which it is permissible for Khan to not pull the four off the track at $t_{1}$ is what's objectionable.)

A proponent of either version of Actualism might try to respond to these objections by noting that in these cases were we to view the agent's future self as morally equivalent to some third party, then she might well be able to deliver the intuitively correct verdicts in these cases. Certainly, if it were the case that Khan's doing PULL would have the result that some third party would turn the trolley away from the two and onto the one, we wouldn't think that that fact would get Khan off the moral hook of having to save the four she can easily save. That's as may be. But pointing to the intuitive verdicts in some other cases is not an adequate response to the Three Drowning- and Trolley-based objections to Actualism. The problem is Actualism's implications in these cases; that it may get the right results in yet other cases doesn't solve that problem.

The Actualist may of course tell a self-consistent story according to which she treats Three Drowning and Trolley as of a piece with cases in which it is a third

42. Again, I'm stipulating this for the purposes of this argument. Any level of other-sacrifice that is permissible but not required in order to save the lives of six innocent people will do.

43. Again, I write ' $\sim$ PULL from $t_{1}$ to $t_{2}^{\prime}$ here instead of '[ $\sim$ PULL \& NOTHING] from $t_{1}$ to $t_{2}$ ' merely for ease of presentation. 
party whose future action is relevant to the agent's present moral obligations. But whether one's own potential future voluntary actions should be treated as morally on a par with those of some other distinct person is precisely the question at issue between the Actualist and the Possibilist. What's more, treating an agent's future self as morally on a par with some other distinct person is out of step with much of the rest of our moral practice. For one example: if I know now, this morning, that later this afternoon I'm going to promise to bring cookies to the party tonight, and starting baking the cookies now, in the morning, is the only way I'll be able to bring cookies to the party tonight, then I ought to, and insofar as I'm morally conscientious I will, start baking the cookies now; but were it some other person who was going to promise in the afternoon that she would bring cookies to the party tonight, it wouldn't follow that I ought to start baking now, nor would it follow that moral conscientiousness entails my starting baking now (and this is true even if my starting baking now were the only way that other person would be able to bring the cookies tonight-we're under no significant standing obligation, nor does moral conscientiousness require us, to ensure that others keep their promises). For another example: whereas I can now consent to your later punching me and thereby make it permissible for you to punch me later (this is, after all, what makes boxing a morally permissible activity), I cannot now consent to your later punching some third party and thereby make your later punching that third party morally permissible.44 These are just some of the many ways in which one's future self is morally disanalogous to that of a distinct individual. One cannot simply appeal to the moral parity of one's future self and some future distinct individual in replying to the Three Drowning- and Trolley-based objections to Actualism.

\section{Conclusion}

I've argued that Actualism and Subjective Possibilism are both untenable. It follows from this that whatever the correct moral theory is it must be an Objective Possibilist one.

\section{Acknowledgments}

I'd like to thank audiences at the University of Massachusetts Amherst and the Australian National University for helpful feedback on predecessors of this paper. I'd also like to thank Liz Harman, Alejandro Pérez-Carballo, and especially

44. Vessel (2015) makes a related point.

Ergo • vol. 6, no. 8 • 2019 
Chris Meacham, as well as two anonymous referees for Ergo and other anonymous referees at other journals, for feedback on and discussion of drafts of this paper.

\section{References}

Bykvist, Krister (2009). Objective versus Subjective Moral Oughts. Uppsala Philosophical Studies, 57, 39-65.

Cohen, Yishai and Travis Timmerman (2016). Moral Obligations: Actualist, Possibilist, or Hybridist? Australasian Journal of Philosophy, 94(4), 672-686.

Feldman, Fred (1986). Doing the Best We Can. D. Reidel.

Goble, Lou (1993). The Logic of Obligation, 'Better' and 'Worse'. Philosophical Studies, $70(2), 133-163$.

Goldman, Holly S. (1976). Dated Rightness and Moral Imperfection. Philosophical Review, $85(4), 449-487$.

Goldman, Holly S. (1978). Doing the Best One Can. In Alvin I. Goldman and Jaegwon Kim (Eds.), Values and Morals (185-214). D. Reidel.

Graham, Peter A. (2010). In Defense of Objectivism about Moral Obligation. Ethics, 121(1), 88-115.

Greenspan, Patricia S. (1978). Oughts and Determinism: A Response to Goldman. Philosophical Review, 87(1), 77-83.

Humberstone, I. L. (1983). The Background of Circumstances. Pacific Philosophical Quarterly, 64, 19-34.

Jackson, Frank (1991). Decision-Theoretic Consequentialism and the Nearest and Dearest Objection. Ethics, 101(3), 461-482.

Jackson, Frank (2014). Procrastinate Revisited. Pacific Philosophical Quarterly, 95(4), 634647 .

Jackson, Frank and Robert Pargetter (1986). Oughts, Options, and Actualism. Philosophical Review, 95(2), 233-55.

Kiesewetter, Benjamin (2011). 'Ought' and the Perspective of the Agent. Journal of Ethics and Social Philosophy, 5(3), 1-24.

Moore, George E. (1903). Principia Ethica. Cambridge University Press.

Portmore, Douglas W. (2011). Commonsense Consequentialism: Wherein Morality Meets Rationality. Oxford University Press.

Prichard, Harold A. (1949). Duty and Ignorance of Fact. In H. A. Prichard Moral Obligation (18-39). Clarendon Press.

Ross, William D. (1939). Foundations of Ethics. Oxford University Press.

Ross, William D. (2002). The Right and the Good. Oxford University Press.

Ross, Jacob (2012). Actualism, Possibilism, and Beyond. In Mark Timmons (Ed.), Oxford Studies in Normative Ethics (Vol. 2, 74-96). Oxford University Press.

Sidgwick, Henry (1907). The Methods of Ethics. Macmillan.

Smith, Holly M. (2014). The Subjective Moral Duty to Inform Oneself before Acting. Ethics, 125(1), 1-28.

Sobel, Jordan Howard (1976). Utilitarianism and Past and Future Mistakes. Noûs, 1o(2), 195-219. 
Thomason, Richmond H. (1981). Deontic Logic and the Role of Freedom in Moral Deliberation. In Risto Hilpinen (Ed.) New Studies in Deontic Logic (177-186). D. Reidel. Thomson, Judith J. (1990). The Realm of Rights. Harvard University Press.

Vessel, Jean-Paul (2009). Defending a Possibilist Insight in Consequentialist Thought. Philosophical Studies, 142(2), 183-195.

Vessel, Jean-Paul (2015). Against Securitism, the New Breed of Actualism in Consequentialist Thought. Utilitas, 28(2), 164-178.

Vorobej, Mark (2000). Prosaic Possibilism. Philosophical Studies, 97(2), 131-136.

Woodard, Christopher (2009). What's Wrong With Possibilism. Analysis, 69(2), 219-226.

Zimmerman, Michael J. (1996). The Concept of Moral Obligation. Cambridge University Press.

Zimmerman, Michael J. (2008). Living with Uncertainty. Cambridge University Press.

Zimmerman, Michael J. (2014). Ignorance and Moral Obligation. Oxford University Press. 